\title{
Gynaecological Illness after Sterilization
}

\author{
M. J. MULDOON
}

British Medical fournal, 1972, 1, 84-85

\section{Summary}

A total of 374 patients were followed up for at least 10 years after tubal ligation, and $43 \%$ required further gynaecological treatment. Major gynaecological surgery was needed by $25 \%$. There seems a good case for the selective use of hysterectomy as a method of sterilization.

\section{Introduction}

In the last decade there has been a considerable increase in the demand for female sterilization for mainly contraceptive purposes, and, particularly since the introduction of the Abortion Act in 1967, many gynaecologists are giving these cases sympathetic consideration. It has now become clear that surgical sterilization as a means of family planning is a lawful operation in Britain provided that informed consent from husband and wife is obtained (British Medical fournal, 1960, 1966; Royal College of Obstetricians and Gynaecologists, 1969).

The increased popularity of sterilization is due to its reliability as a method of contraception, its relative simplicity, and its freedom from unpleasant side effects. This last particularly applies to patients unable or unwilling to use oral contraceptives. Despite these advantages considerable disquiet has been expressed recently on two grounds: firstly, that many reports have indicated that there is a high incidence of subsequent pelvic disease, usually disorders of menstruation, following sterilization by tubal ligation (Williams et al., 1951; Powell, 1962; Chakrovarty, 1966; Rakshit, 1966); and, secondly, that many young wives who have completed their family by the age of 25 years or even less are requesting sterilization (Eton, 1971). Only one follow-up study in the United Kingdom of a relatively small number of patients has been published recently, and this also showed a high incidence of subsequent menstrual disturbance (Whitehouse, 1969). The object of the present study was to investigate the incidence of subsequent pelvic disease which required gynaecological treatment.

\section{Patients and Material}

Case records of all the female patients subjected to sterilization at the two Dundee teaching hospitals during 1955-60 were obtained. These totalled 410 patients. Records of subsequent attendances at the gynaecological outpatient department or admission to the gynaecological wards were also procured. If there was no record of hospital attendance after sterilization the patients were contacted either directly or through their general practitioner and inquiry was made into any gynaecological illness and treatment after tubal ligation. In this way details were obtained of the poststerilization history of 374 patients $(91 \%)$. The remaining 36 either could not be traced or had died in the intervening period. Table I shows the indication for sterilization in the group of patients studied.

While multiparity is listed as the commonest indication for sterilization, socioeconomic factors were often contributing

Department of Obstetrics and Gynaecology, University of Dundee M. J. MULDOON, M.B., CH.B., M.R.C.O.G., Lecturer

TABLE I-Indications for Sterilization in 374 Patients

Multiparity (5 or more children)
Socioeconomic factors (fewer than 5 children)

At caesarean section

Bad obstetric history,

Medical disease (mainly cardiovascular)

Termination of pregnancy (hysterotomy)
Miscellaneous .. .. .. .

causes in these cases, but for the present study multiparity has been defined as five or more children. The patients sterilized at the time of caesarean section were mainly having their third elective section for a recurrent indication such as disproportion, but a few were multigravidae sterilized during their first caesarean section for conditions such as placenta praevia or malpresentation. The cases grouped under bad obstetric history includes cases of recurrent severe pre-eclampsia or eclampsia, severe hypertension, recurrent postpartum haemorrhage, rhesus isoimmunization, and recurrent fetal abnormality, particularly those affecting the central nervous system. The medical indications for sterilization were mainly rheumatic heart disease, renal disease, diabetes mellitus, and pulmonary diseases. The miscellaneous group contained indications such as mental subnormality, psychiatric illness, recent malignancy, and three patients having a Manchester type of repair for prolapse.

Most of the tubal ligations performed were of the Pomeroy type but a few Madlener operations were performed; in a few cases the type of operation was not recorded. Sixty tubal ligations were carried out either at caesarean section or at hysterotomy, 144 were carried out in the puerperium, usually between the second and fourth puerperal days, and 170 were interval procedures, three being performed at elective operation for prolapse.

Of the 374 patients studied $162(43 \%)$ gave a history of subsequent gynaecological treatment. Hysterectomy was performed in 70 of these $(18.7 \%)$, the indications being shown in Table II. The details of gynaecological therapy in the remaining 92 are shown in Table III.

It will be noted from Table III that two patients in the series-one who had a Pomeroy type sterilization at her third

TABLE II-Indications for Operation in 70 Patients Previously Sterilized Who Required Hysterectomy

Severe menstrual disorders (mainly menorrhagia) .. Pelvic inflammatory disease * Carcinoma of cervix

Vaginal hysterectomy with repair of prolapse

Fibroids causing symptoms

Endometriosis .

* Includes three cases of carcinoma-in-situ treated by hysterectomy with removal of a cuff of vagina and two cases having Wertheim's hysterectomy performed after radium for invasive carcinoma.

TABLE III-Patients Previously Sterilized Requiring Gynaecological Treatment Other than Hysterectomy

\begin{tabular}{|c|c|c|c|}
\hline \multirow{2}{*}{ Indication } & \multirow{2}{*}{ Treatment } & \multicolumn{2}{|c|}{ Patients } \\
\hline & & No. & $\%$ \\
\hline $\begin{array}{l}\text { Menorrhagia/Metrorrhagia } \\
\text { Prolapse or stress incontinence } \\
\text { Menstrual disturbance or } \\
\text { dysmenorrhoea } \\
\text { Cervical erosion } \\
\text { Ovarian neoplasm } \\
\text { Failed sterilization }\end{array}$ & $\begin{array}{l}\text { Dilatation and curettage } \\
\text { Repair of prolapse } \\
\text { (uterine or vaginal) } \\
\text { Hormonal therapy } \\
\text { Cauterization of cervix } \\
\text { Oophorectomy } \\
\text { Repeat sterilization }\end{array}$ & $\begin{array}{r}21 \\
20 \\
3 \\
2\end{array}$ & $\begin{array}{l}6.4 \\
5.9 \\
\\
5.6 \\
5.4 \\
0.8 \\
0.5\end{array}$ \\
\hline & Total & 92 & \\
\hline
\end{tabular}

Note. If more than one operation was carried out the most significant was notedfor example, cautery to the cervix was usually accompanied by curettage. 
caesarean section and the other a gravida- 5 who had a puerperal sterilization performed-subsequently became pregnant. The first patient had a bilateral salpingectomy performed at repeat caesarean section and the second a repeat Pomeroy ligation three months after delivery.

When the 70 patients who required hysterectomy subsequent to sterilization were looked at separately it was noted that 50 of them were gravida- 5 or more, 15 had been subjected to repeat caesarean section and sterilization, and three were sterilized at the time of hysterotomy. Of the 22 patients requiring repair of prolapse 20 had had four or more confinements.

\section{Discussion}

The findings in this study confirm those of others that there is a relatively high incidence of subsequent pelvic disease in patients subjected to tubal ligation. The incidence of subsequent gynaecological consultation and treatment in this study was $43 \%$. A total of 95 patients $(25 \%)$ required further major gynaecological surgery. The commonest symptom was menstrual disturbance, and more than 90 patients were treated for this, 49 requiring hysterectomy for control. Williams et al. (1951) suggested primary hysterectomy as the treatment of choice in all patients desiring or requiring sterilization, but it is felt that this is too major a procedure for every patient. This study shows that most patients requiring further major surgery were either highly multiparous or had had surgical wounds in the uterus either at caesarean section or hysterotomy.

The fact that there is a relatively high incidence of subsequent hysterectomy in patients having caesarean sections has already been noted. Weeds (1959) found that $14 \%$ of his patients who had had a caesarean section ultimately came to hysterectomy, and several American authors (Montague, 1959; Pletsch and Sandberg, 1963) have suggested that patients who have been subjected to several caesarean sections and who wish to be sterilized should have elective caesarean hysterectomy at delivery in their last pregnancy. Owing to the high incidence of complications, such as bladder injury and postoperative haematoma formation following the operation, this is unlikely to be adopted in this country. It would seem reasonable, however, in highly parous patients requesting or requiring sterilization to take a careful menstrual history, and those who have had previous menstrual disorders even before a present pregnancy might well be better treated by hysterectomy, if necessary delaying operation until complete involution of the pelvic organs has taken place. If there is evidence of prolapse vaginal hysterectomy and repair, where feasible, would seem to be the procedure of choice. The occurrence of five cases of cervical carcinoma (three of these lesions in situ) emphasizes the importance of checking cervical cytology before operation.

I would like to thank Professor James Walker for his interest and encouragement during the course of this study, Mrs. Frances Dunn for her help with the follow-up, and Miss Carol Hewat for secretarial assistance.

\section{References}

British Medical fournal, 1960, 2, 1516.

British Medical fournal, 1966, 1, 1597.

Chakrovarty, S. (1966). Fournal of Obstetrics and Gynaecology of India, 12,448 .

Eton, B. (1971). British Medical fournal, 2, 526.

Montague, C. F. (1959). Obstetrics and Gynecology, 14, 29.

Pletsch, D. T., and Sandberg, E. C. (1963). American fournal of Obstetrics and Gynecology, 85, 254.

Powell, L. (1962). Obstetrics and Gynecology, 19, 387.

Rakshit, B. (1966). Fournal of the Indian Medical Association, 3, 95.

Royal College of Obstetricians and Gynaecologists (1969). Fournal of Obstetrics and Gynaecology of the British Commonwealth, 76, 1042.

Weed, J. C. (1959). Obstetrics and Gynecology, 14, 780.

Whitehouse, D. B. (1969). Advances in Fertility Control, 1, 22.

Williams, E. L., James, H. G., and Merrill, R. E. (1951). American fournal of Obstetrics and Gynecology, 61, 423.

\section{PRELIMINARY COMMUNICATIONS}

\section{Carcinoembryonic Antigen in Faeces}

\section{L. J. FREED, GEOFFREY TAYLOR}

British Medical Gournal, 1972, 1, 85-87

\section{Summary}

Carcinoembryonic antigen (C.E.A.) was detected in the faeces of 5 out of 10 healthy volunteers, 12 out of 18 patients suffering from gastrointestinal cancer (including 10 out of 11 cases of colonic cancer), and 3 out of 13 patients suffering from non-neoplastic disease. It is suggested that C.E.A. may be present in small amounts in normal faeces but that in malignant conditions of the bowel the amount increases.

\footnotetext{
Immunology Laboratories, University Department of Bacteriology and Virology, Manchester M13 9PL

D. L. J. FREED, M.B., CH.B., Lecturer

G. TAYLOR, M.D., Reader
}

\section{Introduction}

Carcinoembryonic antigen (C.E.A.) is the name given by Gold and Freedman to a protein-polysaccharide complex of sedimentation coefficient 6.9 to $8.0 \mathrm{~S}$ which is present in epithelial cell membranes of fetal gastrointestinal structures, disappears at about six months' gestation, and in the adult is found in adenocarcinomata of the gastrointestinal tract (Gold and Freedman, 1964, 1965; Krupey et al., 1968; Gold et al., 1968). The demonstration by Thomson et al. (1969), using a radioimmunoassay technique, of circulating C.E.A. in the serum of 35 out of 36 patients with colonic or rectal cancer but not in sera from patients with a wide variety of other complaints suggested that the method might be used as a diagnostic test for bowel cancer. In the hands of Moore et al. (1971), however, the test appeared to be less specific. Though they confirmed the finding of circulating C.E.A. in patients with colonic cancer the test was also positive in several cases of lung cancer, alcoholic liver disease, and uraemia, and Lo Gerfo et al. (1971), while again confirming the results of Thomson et al. (1969) with respect to colonic cancer, also found circulating C.E.A. in a few cases of non-neoplastic bowel and lung disease as well as cancers of the breast, ovary, uterus, bladder, prostate, and kidney.

Since the turnover of epithelial cells in the intestine is so high it seemed logical to look for C.E.A. in the faeces of patients with gastrointestinal cancer, where C.E.A. of extra-alimentary origin would be unlikely to be present. 